\title{
PAPEL DOS PROFISSIONAIS DE SAÚDE NA POLÍTICA DE HUMANIZAÇÃO HOSPITALAR
}

\author{
Roberta Araújo Mota* \\ Cileide Guedes de Melo Martins \\ Renata Meira Véras
}

\begin{abstract}
RESUMO. O interesse por este tema surgiu a partir de uma reflexão sobre o papel do profissional de saúde nos atendimentos realizados no ambiente hospitalar, tendo como meta transmitir para esses profissionais informações sobre os cuidados de saúde de uma maneira mais simples e humanizada, e assim levar o bem-estar a todos. O governo adota uma política legal e ética com relação à saúde no país, possuindo um papel fundamental no processo de humanização. Com a proposta de melhorar a qualidade do atendimento nos hospitais, percebemos que estas atividades requerem tempo e conscientização tanto dos profissionais como do governo e pessoas envolvidas no sistema de saúde. Diante desta situação, o psicólogo surge com o papel de resgatar o ser humano para além de sua dimensão físico-biológica e situá-lo num contexto maior de sentido e significado nas suas dimensões psíquicas e sociais.
\end{abstract}

Palavras-chave: psicólogo, humanização, hospital.

\section{THE ROLE OF HEALTH PROFESSIONALS IN POLICIES REGARDING HOSPITAL HUMANIZATION}

\begin{abstract}
The interest on this theme emerged from a reflection on the role of health professionals in relation to the attendance carried out in hospitals. Thus, the aim is to transmit other pieces of information to these professionals, regarding health concerns, in a simpler and humanized way, thereby, leading to an atmosphere of well-being to the whole group or working team. Government adopts legal and ethics policies in relation to the heath in the country, holding a fundamental role in the humanization process. When aiming at improving the quality of hospital service, it was noticed that such activities require time and understanding on part of: professionals, government and also on part of all the people involved in the health system. Thus, the psychologist appears, with the purpose of rescuing the human being, beyond their physic-biological dimension, placing them into a bigger context of senses and meanings regarding their psychic and social dimensions.
\end{abstract}

Key words: Psychologist, humanization, hospital.

\section{PAPEL DE LOS PROFESIONALES DE SALUD EN LA POLÍTICA DE HUMANIZACIÓN HOSPITALARIA}

RESUMEN. El interés por este tema surgió a partir de una reflexión sobre el papel del profesional de salud en los atendimientos realizados en el ambiente hospitalario, teniendo como meta transmitir a estos profesionales informaciones sobre los cuidados de salud de una manera más simple y humanizada, y así, proporcionar bienestar a todos. El Gobierno adopta una política legal y ética con relación a la salud en el país, teniendo un papel fundamental en el proceso de humanización. Con la propuesta de mejorar la calidad del atendimiento en los hospitales, percibimos que estas actividades requieren tiempo y concienciación, tanto de los profesionales como del Gobierno y personas involucradas en el sistema de salud. Ante esta situación, el psicólogo surge con el papel de rescatar el ser humano más allá de su dimensión físico-biológica y ubicarlo en un contexto mayor de sentido y significado en sus dimensiones psíquicas y sociales.

Palabras-clave: psicólogo, humanización, hospital.

* Psicóloga. Especialista. Faculdade de Ciências Sociais Aplicada-Facisa, João Pessoa-PB.

\# Psicóloga. Mestre. Professora da Fatec, Paraíba. 


\section{NECESSIDADE DE HUMANIZAÇÃO COMO POLÍTICA DE SAÚDE}

O contato direto com seres humanos coloca o profissional de saúde diante de sua própria vida, saúde ou doença, dos próprios conflitos e frustrações. Se ele não tomar contato com esses fenômenos, correrá o risco de desenvolver mecanismos rígidos de defesa que podem prejudicá-lo tanto no âmbito profissional quanto no pessoal, como também este profissional da saúde, ao entrar em contato com os seres humanos, pode utilizar o distanciamento como mecanismo de defesa.

Muitos profissionais de saúde submetem-se, em sua atividade, a tensões provenientes de várias fontes: contato freqüente com a dor e o sofrimento e com pacientes terminais, receio de cometer erros, relações com pacientes difíceis. Sendo assim, cuidar de quem cuida é condição suficiente para desenvolver projetos de ações em prol da humanização da assistência.

Segundo Martins (2001), a humanização é um processo amplo, demorado e complexo, ao qual se oferecem resistências, pois envolve mudanças de comportamento, que sempre despertam insegurança. Os padrões conhecidos parecem mais seguros; além disso, os novos não estão prontos nem em decretos nem em livros, não tendo características generalizáveis, pois cada profissional, cada equipe, cada instituição terá seu processo singular de humanização.

Com o passar dos anos, devido à necessidade de mudança nas políticas de saúde, muitos projetos de humanização vêm sendo desenvolvidos, há vários anos, em áreas específicas da assistência - por exemplo, na saúde da mulher, na humanização do parto e na saúde da criança com o projeto mãe-canguru, para recémnascidos de baixo peso. Atualmente têm sido propostas diversas ações visando à implantação de programas de humanização na assistência pediátrica, vários projetos e ações desenvolvem atividades ligadas a artes plásticas, música, teatro, lazer, recreação.

Destarte, a teia inter-relacional, ou seja, o conjunto das relações que se estabelecem nas instituições - como profissional-paciente, recepção-paciente, profissionalequipe, profissional-instituição e outros - necessita da humanização (Martins, 2001).

Acreditamos que a humanização deva caminhar cada vez mais, para se constituir como vertente orgânica do sistema clínico de saúde. Como política ela deve traduzir princípios e modos de operar no conjunto das relações entre profissionais e usuários, entre os diferentes profissionais e entre as diversas unidades e serviços de saúde.
Tomar a saúde como valor de uso é ter por padrão o vínculo com os usuários, garantindo direitos a eles e aos seus familiares; é estimular que os usuários se coloquem como protagonistas do sistema de saúde; mas é também os profissionais terem melhores condições de realizar seu trabalho de modo digno e criador de novas ações, possibilitando-lhes participar como co-gestores de seu processo de trabalho.

Segundo a Política Humaniza SUS, a humanização supõe troca de saberes, incluindo os dos usuários e sua rede social, diálogo entre os profissionais e modos de trabalhar em equipe (Brasil, 2005).

Sendo assim, entendemos a humanização como estratégia de interferência no processo de produção de saúde, levando em conta que sujeitos sociais, quando mobilizados, são capazes de modificar realidades, transformando-se a si próprios neste mesmo processo. Trata-se, sobretudo, de investir na produção de um novo tipo de interação entre os sujeitos que constituem os sistemas de saúde e deles usufruem, acolhendo tais atores e formulando seu protagonismo.

Enfim, a humanização estabelece-se como construção de atitudes ético-estético-políticas em sintonia com um projeto de co-responsabilidade e qualificação dos vínculos entre os profissionais e entre estes e os usuários na produção de saúde (Freyre, 2004).

De acordo com a Política Humaniza SUS, o SUS deve ser contagiado por esta atitude humanizadora, articulando-se através deste eixo. Trata-se, sobretudo, de destacar o aspecto subjetivo presente em qualquer ação humana, em qualquer prática de saúde (Brasil, 2005).

Podemos dizer que a rede de humanização em saúde é uma rede de construção permanente de laços de cidadania, de um modo de olhar cada sujeito em sua especificidade, sua história de vida, mas também de olhá-lo como sujeito de um coletivo, sujeito da história de muitas vidas.

De acordo com Lepargneur (2003), humanizar é saber promover o bem comum acima da suscetibilidade individual ou das conveniências de um pequeno grupo.

Para Pessini (2002) é possível e adequado para a humanização se constituir, sobretudo, na presença solidária do profissional, refletida na compreensão e no olhar sensível, aquele olhar de cuidado que desperta no ser humano sentimento de confiança e solidariedade.

Construir uma metodologia de trabalho para implantação de projetos de humanização nas diversas instituições favorecerá o desenvolvimento de ações 
voltadas para os usuários e condições de trabalho para os profissionais, fortalecendo espaços de troca e produção de conhecimento voltado para uma melhor qualidade de trabalho e saúde.

Então, o que é humanizar? Entendido assim, humanizar é garantir à palavra a sua dignidade ética; ou seja, para que o sofrimento humano e as percepções de dor ou de prazer no corpo sejam humanizados, é preciso tanto que as palavras expressas pelo sujeito sejam entendidas pelo outro quanto que este ouça do outro palavras de seu conhecimento. Pela linguagem, fazemos as descobertas de meios pessoais de comunicação com o outro, sem o que nos desumanizamos reciprocamente (Buss, 2000). Sem comunicação não há humanização. A humanização depende de nossa capacidade de falar e ouvir, do diálogo com nossos semelhantes.

O desenvolvimento científico e tecnológico tem trazido uma série de benefícios, sem dúvida, mas tem como efeito adverso o incremento da desumanização. $\mathrm{O}$ preço que pagamos pela suposta objetividade da ciência é a eliminação da condição humana da palavra, que não pode ser reduzida a mera informação de anamnese. Por exemplo, quando preenchemos uma ficha de histórico clínico, não estamos escutando a palavra, mas apenas recolhendo a informação necessária para o ato técnico. Este é indispensável, sem dúvida, mas o lado humano fica excluído. $\mathrm{O}$ ato técnico, por definição, elimina a dignidade ética da palavra, pois esta é necessariamente pessoal, subjetiva, e precisa ser reconhecida na palavra do outro (Ballint, 1975).

A dimensão desumanizante da ciência e tecnologia se dá, destarte, na medida em que ficamos reduzidos a objetos de nossa própria técnica e objetos despersonalizados de uma investigação que se propõe ser fria e objetiva. Um hospital pode ser excelente na questão da tecnologia e mesmo assim ser desumano no atendimento, por tratar as pessoas como simples objetos de intervenção técnica, sem serem ouvidas em suas angústias, temores e expectativas, ou sequer informadas sobre o que está sendo feito com elas, pois o saber técnico define em consiste o bem do paciente, independentemente de sua opinião.

Por outro lado, o problema em muitos outros locais é justamente a falta de condições técnicas, seja de capacitação, seja de materiais. Tais locais se tornam desumanizantes pela má qualidade resultante do atendimento e sua baixa resolubilidade. Essa falta de condições técnicas e materiais também pode induzir à desumanização, na medida em que profissionais e usuários se relacionem de forma desrespeitosa, impessoal e agressiva, piorando uma situação que já é precária.

De acordo com a Política Nacional de Humanização (Brasil, 2005), a humanização é um pacto, uma construção coletiva que só pode acontecer a partir da construção e troca de saberes, através do trabalho em rede com equipes multiprofissionais, da identificação das necessidades, desejos e interesses dos envolvidos, do reconhecimento de gestores, trabalhadores e usuários como sujeitos ativos e protagonistas das ações de saúde, e da criação de redes solidárias e interativas, participativas e protagonistas do SUS.

A Rede de Humanização em Saúde é, desta forma, uma permanente construção de laços de cidadania, onde há a valorização de todos os sujeitos implicados no processo de produção de saúde, o fomento da autonomia e da co- responsabilidade, o estabelecimento de vínculos solidários e de participação coletiva no processo de gestão, o empenho na mudança dos modelos de atenção e gestão vigentes e o compromisso com o meio ambiente e com a melhora das condições de atendimento e de trabalho (Brasil, 2005).

Através da consolidação e da expansão dos Grupos de Trabalho de Humanização, o SUS traça metas que visam reduzir as filas e o tempo de espera para atendimento. Espera-se que este procedimento seja acolhedor e facilite a identificação, pelo usuário, dos profissionais que dele cuidam, o seu acesso à informação e seu direito de acompanhamento de pessoas de sua rede social, a educação continuada dos profissionais e a gestão participativa dos trabalhadores e usuários.

\section{HUMANIZAÇÃO NO HOSPITAL}

O movimento de humanização nos hospitais é voltado para o processo de educação e treinamento dos profissionais de saúde, mas também para intervenções estruturais que façam a experiência da hospitalização ser mais confortável para o paciente.

Ballint (1975) afirma que todo médico tem uma vaga idéia, porém quase inabalável, de como seu paciente deve se comportar e o que esperaria ou suportaria, ao que ele chamou "função apostólica", visto que o médico acreditaria poder ensinar o que é certo ao paciente. $\mathrm{O}$ médico tende a perceber os problemas físicos, psicológicos e sociais do paciente de acordo com sua própria hierarquia de valores e prioridades, que geralmente é diferente da percepção que tem o próprio paciente, e estas diferenças pessoais, culturais e históricas entre eles dificultam a 
comunicação entre ambos, prejudicando o paciente na expressão de suas necessidades.

Como se não bastassem os problemas de comunicação existentes entre médicos e pacientes, ainda existe nos hospitais públicos o "conluio do anonimato", que é a situação na qual o paciente é atendido por vários médicos e decisões vitais são adotadas sem que nenhum desses profissionais se responsabilize por ele, nem observe o resultado de suas próprias recomendações (Brasil, 2005).

Por outro lado, o doente, ao ser hospitalizado, onera a sociedade, uma vez que necessita de assistência, deixa de ser capaz de trabalhar e sua família pode ficar exposta à miséria e à doença. Esta separação dos doentes através da hospitalização, destinada a proteger, termina por comunicar a doença e multiplicá-la.

A proposta de humanização da assistência à saúde visa à melhoria da qualidade de atendimento ao usuário e das condições de trabalho para os profissionais. Sabemos que visa, também, ao alinhamento com as políticas mundiais de saúde e à redução dos custos excessivos e desnecessários decorrentes da ignorância, do descaso e do despreparo que ainda permeiam as relações de saúde em todas as instâncias (Brasil, 2005).

Pesquisas realizadas em hospitais (Martins, 2001; Mazzetti, 2005) mostram que quando se trabalha com humanização a melhora do ambiente hospitalar traz benefícios como a redução do tempo de internação, aumento do bem-estar geral dos pacientes e funcionários e diminuição das faltas de trabalho entre a equipe de saúde, e, como conseqüência, o hospital também reduz seus gastos, trazendo benefícios para todos.

Hoje, já é nítida a percepção de muitas instituições quanto à necessidade de incorporar diretrizes e projetos de humanização para funcionários e pacientes, principalmente no ambiente hospitalar.

Não obstante, segundo Mazzetti (2005), pesquisas científicas na área da humanização são poucas; mas já existem projetos do Governo Federal - como o Humaniza SUS, o, "cuidando dos cuidadores", "doutores da alegria", mediante os quais muitas crianças passam a ver a situação de hospitalização de forma mais positiva e menos persecutória, ou seja, as crianças começam a se comunicar mais, alimentar-se melhor e a colaborar com a equipe de saúde, facilitando assim o trabalho dos profissionais, o que lhes propicia uma melhor qualidade de.

De acordo com Martins (2001), para uma avaliação da complexidade da tarefa assistencial, em especial da realizada em hospitais, deve-se levar em conta que o paciente está inserido em um contexto pessoal, familiar e social complexo e que a assistência deve efetuar uma leitura das necessidades pessoais e sociais do paciente. Portanto, nesta instituição, interagem as necessidades de quem assiste e as de quem é assistido.

Partindo desta avaliação, as reflexões sobre a tarefa assistencial conduzem também ao campo ético. A ética surge quando alguém se preocupa com a conseqüência de sua conduta sobre o outro. Para que exista ética, é necessário perceber o outro; e se para a assistência humanizada também é preciso ver o outro, conclui-se então que a assistência humanizada e a ética caminham juntas.

De acordo com Couto (2005), os pacientes de hospitais públicos têm sobre estes a imagem já formada de estabelecimentos onde faltam médicos e o atendimento é ruim. Qualquer tipo de atenção dada a este paciente é muito baixo. Além disso, na maioria das vezes a relação médico-paciente acaba sendo de subordinação, porque o cliente se sente discriminado por causa de sua condição social.

Acreditamos que profissionais que trabalham com o ser humano devem tratar o outro como humano, isto é, com igualdade, aproximação, tentando fazer o melhor, respeitá-lo e acompanhá-lo. Devem desenvolver as ações necessárias para a humanização, de modo a possibilitar mudanças no tratamento hospitalar. Para o processo de humanização hospitalar acontecer, médicos, corpo de diretores, enfermeiros e pacientes devem estar envolvidos de forma harmônica.

Hoje, devido à humanização nos hospitais realizada por profissionais, pacientes e familiares, estes últimos encontram no centro hospitalar um lugar que ameniza o sofrimento e diminui a tensão vivida por eles, durante o processo de tratamento. Com a proposta de melhorar a qualidade do atendimento, muitos hospitais vêm aderindo ao trabalho voluntário para minimizar os efeitos que as doenças provocam nos pacientes. 0 trabalho voluntário em hospitais é um dos fatores fundamentais para a humanização do atendimento. Ele dá suporte emocional aos pacientes, além de ser facilitador do trabalho dos departamentos clínicos e administrativos dos hospitais.

A humanização no hospital é importante, pois o paciente passa a ser tratado como pessoa que é, com todos os tipos de sentimento que a interação pode suscitar, e não mais como apenas um doente (Duarte, 2005).

Segundo Jeammet e Consoli (2000), humanizar é reintroduzir o humano no funcionamento do hospital, 
quer dizer, evitar que este último seja reduzido ao papel de usina para reparar órgãos danificados.

A humanização no hospital deve partir do princípio de que cada paciente necessita continuar vivendo como ser humano; ou seja, deve levar em consideração seus valores de referência, solicitando ao máximo o conjunto de suas possibilidades de funcionamento, não somente as fisiológicas, mas igualmente as mentais. Deve evitar que o paciente seja desorganizado pela angústia e submergido por suas reações emocionais e facilitar seu acesso à palavra é a possibilidade de unir e de simbolizar seus afetos (Jeammet \& Consoli, 2000).

A precariedade em que os serviços públicos vivem hoje contribui - e muito - para o fortalecimento de planos de saúde e de hospitais particulares, onde só se entra caso se tenha plano de saúde ou recursos financeiros próprios consideráveis.

Nos hospitais públicos e filantrópicos, pelo menos quando existem vagas, a consideração que determina a admissão ou não do doente ao hospital é sua necessidade de ser tratado; mas no hospital particular, o fator determinante para admissão não é a enfermidade da pessoa e sua necessidade de ser tratada, mas sim, a validade do seu plano de saúde e a saúde do seu bolso. Se possuir os recursos financeiros adequados, o tratamento pode até ser de primeira qualidade, mas se não os possui, nem entra no estabelecimento (Pessini \& Bertachini, 2004).

A preocupação com a humanização hospitalar tem como principal meta a dignidade do ser humano e o respeito por seus direitos, visto que a pessoa humana deve ser considerada em primeiro lugar. A dignidade da pessoa, sua liberdade e seu bem-estar são todos fatores a serem ponderados na relação entre o doente e o profissional da saúde.

Continua a ser importante curar doenças, mas sem esquecer que mais importante ainda é curar o doente; e não somente curá-lo, mas também cuidar dele. É a pessoa doente que deve ser o principal foco de atenção, e não a sua enfermidade. Ainda quando a cura não é mais possível, quando a ciência se acha incapaz de resolver o problema trazido pela doença, continuamos diante do doente, na sua dignidade, na sua fragilidade e na sua necessidade de ser amparado, cuidado e amado (Pessini \& Bertachini, 2004).

Estes autores salientam ainda que, na visão da humanização hospitalar, é importante trabalhar a atitude dos profissionais da saúde tendo-se como primeiro passo deixar de pensar e falar do doente como se fosse um mero objeto de cuidados terapêuticos, um número sem nome. A humanização do hospital começa com o conceito da saúde como bem-estar do indivíduo, da pessoa doente, que é promovido em todas as dimensões: física, mental, social e espiritual.

Para que isso dê certo, o trabalho deve ser de toda a equipe, envolvendo profissionais e voluntários todos comprometidos com a dignidade do ser humano e com a promoção do seu bem-estar integral.

Uma das características da humanização hospitalar é a autonomia do paciente, de maneira que ele possa participar das decisões sobre o tratamento a ser realizado, o ambiente em que vai permanecer durante seu internamento, o que ele irá comer, quando e como irá dormir.

Sem dúvida, a humanização hospitalar tem como principal característica o cuidado do ser humano doente e a promoção da sua saúde entendida como bem-estar completo, isto é, físico, mental, social e espiritual, e terá como uma das suas prioridades a beneficência, que representa fazer o bem ao doente internado.

Outra característica importante da humanização hospitalar é a justiça, cujas normas exigem que a dignidade fundamental do ser humano seja respeitada e que os iguais sejam tratados com igualdade. É justamente esta falta de justiça no sistema hospitalar brasileiro que provoca certa indignação ética, que clama por uma maior humanização deste sistema.

No hospital, essa igualdade em dignidade e direitos fundamentais deve ser respeitada, e deve-se estabelecer um padrão mínimo de atendimento para todos.

Faz parte da humanização hospitalar a criação de condições que respeitem o direito das pessoas a um ambiente humano propício a viver com dignidade e a morrer com tranqüilidade, quando a hora chegar.

Segundo Lepargneur (2003), a humanização hospitalar começa com a qualidade humana das relações entre todos os seus agentes ou funcionários.

Para fazer o diferencial nas relações do cuidado humanizado, no ambiente hospitalar, requer-se do profissional da saúde que atue com humanização solidária e sensibilidade, além de ter postura correta de dignidade de caráter (Pessini \& Bertachini, 2004).

\section{PAPEL DO PSICÓLOGO NO AMBIENTE HOSPITALAR}

O trabalho dos profissionais da psicologia no hospital é lidar com sentimentos, pois o indivíduo, ao sair do contexto familiar, passa a assumir a condição de paciente, perdendo sua autonomia e independência. 
Percebe-se que a humanização hospitalar necessita de um profissional de Psicologia a serviço dos pacientes que se encontram internados, pois esse serviço se torna muito importante durante o tratamento e a recuperação dos pacientes. A doença muitas vezes provoca reações psicológicas graves - como ansiedade, medo, insegurança, depressão, entre outras -, apenas solucionáveis mediante ação desses profissionais.

A contribuição da Psicologia no contexto da saúde, notadamente no âmbito hospitalar, foi de extrema importância nestes últimos anos para resgatar o ser humano para além de sua dimensão físico-biológica e situá-lo num contexto maior de sentido e significado nas suas dimensões psíquica, social e espiritual (Pessini \& Bertachini, 2004).

Neste caso, o psicólogo deve ir além da aparência, valorizando aspectos qualitativos dos fenômenos presentes na vida de cada paciente. Compreender o significado da vida no processo do cuidado inclui não somente atribuições técnicas do profissional, mas também capacidade de perceber e compreender o ser humano, como ele está em seu mundo, como desenvolve sua identidade e constrói a sua própria história de vida.

Concordamos com Pessini e Bertachini (2004) quando dizem que o ambiente hospitalar gera insegurança e uma peculiar ansiedade. Ele é quase sempre um lugar de sofrimento e dor, de espera e angústia, quando não de desolação e desesperança. Nem sempre os pacientes dos serviços de saúde participam das decisões sobre sua vida pessoal, tampouco das políticas de saúde desenvolvidas. Os profissionais, na verdade, "não fazem questão" de abrir espaço e repartir com seus pacientes a responsabilidade de cuidar de sua vida e gerir seu destino.

É por essa razão que um trabalho realizado com os profissionais do setor de Psicologia vai propor a discussão das reais condições de humanização no ambiente hospitalar, engajando-se no papel de cuidador, com o desejo de melhorar o sistema de assistência.

O psicólogo deve ampliar sua compreensão, perceber os elos que unem as pessoas à sua volta, captar seus desejos, vontades e sentimentos.

Para Jeammet e Consoli (2000), a hospitalização apresenta, por si mesma, condições suficientes para induzir um efeito de estresse e de desorganização do controle emocional do paciente. Por isso, no momento da internação o doente se encontra vulnerável, e não é difícil, mesmo se não vivenciarmos tal situação, imaginar o que pode ser a angústia dele ao chegar à emergência de um hospital, passando por situações de inquietação sobre a natureza da afecção, de distanciamento da família e precipitação num mundo desconhecido, sem falar das repercussões dos efeitos físicos da doença.

O papel do psicólogo hospitalar será desenvolvido a partir do encontro com o paciente, no sentido de resgatar sua essência de vida que foi interrompida pela doença e consequiente internação. Fundamentada numa visão humanística com especial atenção aos pacientes e familiares, a psicologia hospitalar considera o ser humano em sua globalidade e integridade, única em suas condições pessoais, com seus direitos humanos definidos e respeitados (Angerami, 2001).

Com o passar do tempo os hospitais passaram a considerar importante e necessário o trabalho do psicólogo nas enfermarias e ambulatórios para atender de forma humanizada os pacientes e compreender a relação dos profissionais com o paciente e com os familiares, sabendo que muitas vezes a angústia ou a depressão do doente refere-se à fragilidade do corpo, sofrimento, invalidez e medo de internação, estabelecendo então dificuldade na relação entre médico e paciente.

De acordo com Angerami (2001), como profissional de saúde, o psicólogo deve observar e ouvir com paciência a linguagem verbal e não-verbal dos pacientes, já que ele é quem mais pode oferecer, no campo da terapêutica humana, a possibilidade de confronto do paciente com sua angústia e sofrimento na fase da hospitalização, buscando superar os momentos de crise.

Uma das atribuições do psicólogo hospitalar é buscar informações sobre a história do paciente, lembrando sempre que o diagnóstico, o prognóstico e técnicas de intervenção só terão importância ao se considerar que não se trata só de doenças, mas sim, de pessoas doentes. Nesse sentido, desconhecer a história da pessoa equivale a negligenciar o próprio sentido do trabalho do psicólogo dentro do hospital (Angerami, 1994).

Nesse aspecto, uma importante coleta de informações pode dar as perspectivas do processo relacional entre o profissional e o paciente. Da mesma forma que em outros processos de entrevista e coleta de informações sobre o paciente, a perspectiva da escuta do psicólogo possibilita a compreensão dos conteúdos latentes e manifestos das queixas do paciente.

A humanização do atendimento por parte dos psicólogos nos hospitais envolve observar todos os aspectos ligados ao adoecer, o respeito aos temores, 
crenças e fragilidades dos pacientes e de seus familiares. Aumentar a integração da equipe técnica com os usuários, promover uma diminuição na angústia e na tensão, constituem meios eficazes para se mudar a impressão prevalente da população sobre os hospitais, fazendo com que os usuários passem a ver o hospital como um lugar que tenta oferecer condições para a manutenção de uma boa saúde ou a sua recuperação (Pessini \& Bertachini, 2004).

O trabalho do psicólogo hospitalar está voltado também a favorecer um apoio à equipe de saúde e orientar adequadamente os familiares que acompanham o paciente.

Sebastiani e Chiatone (1991) afirmam que o psicólogo não está apenas atrás de um diagnóstico no sentido formal e acadêmico do termo, mas sim, à busca da visão ampla possível de quem é e como está o paciente frente ao seu processo de doença, internação hospitalar e tratamento, tendo como o principal objetivo resgatar a visão do indivíduo como um todo, como um ser biopsicossocioespiritual, que tem como princípio básico da própria existência o direito inalienável à dignidade e ao respeito.

No hospital o psicólogo atua, quase sempre, também em situações de crise e emergência, considerando-se que a pessoa hospitalizada passa por novas situações de adaptação e mudança no seu dia-a-dia, quando se instalam muitas vezes regressões emocionais, negação da realidade, dependência, impotência, sentimentos que advêm da própria rotina de hospitalização do indivíduo. $\mathrm{O}$ psicólogo tem por função entender e compreender o que está envolvido na queixa, no sintoma e na patologia, para ter uma visão ampla do que está se passando com o paciente e ajudá-lo a enfrentar esse difícil processo, bem como dar à família e à equipe de saúde subsídios para uma compreensão melhor do momento de vida da pessoa enferma. Como profissional de saúde, o psicólogo tem, portanto, que observar e ouvir pacientemente as palavras e silêncios, já que ele é quem mais pode oferecer, no campo da terapêutica humana, a possibilidade de confronto do paciente com sua angústia e sofrimento na fase de sua doença, buscando superar os momentos de crise.

Pessini e Bertichini (2004) relatam que a humanização no atendimento exige dos profissionais da saúde, essencialmente, compartilhar com seu paciente experiências e vivências que resultem na ampliação do foco de suas ações, via de regra restritas ao cuidar como sinônimo de ajuda às possibilidades da sobrevivência. Dessa forma, cada encontro entre o profissional de atendimento humanizado e o paciente reveste-se de uma tomada de consciência quanto aos valores e princípios norteadores de suas ações, num contexto relacional.

Há muito a fazer em termos de operacionalização de políticas públicas relacionadas com a saúde, bem como com a necessidade de intervir no aparelho formador de profissionais para criar uma nova cultura. Felizmente a reflexão avança, à medida que estimula os profissionais da saúde, juntamente com a sociedade, a debater este contexto.

Conclui-se que, para a construção de uma política de qualificação da saúde, a humanização deve ser vista como uma das dimensões fundamentais, não podendo ser entendida como apenas um programa a mais a ser aplicado aos diversos serviços de serviço, mas como uma política que opere transversalmente em toda a rede de serviço hospitalar do Brasil.

\section{REFERÊNCIAS}

Angerami, C. V. A. (1994). Psicologia hospitalar: teoria e prática. São Paulo: Pioneira.

Angerami, C. V. A. (2001). E a Psicologia entrou no hospital. São Paulo: Pioneira.

Ballint, M. (1975). O médico, seu paciente e a doença. Rio de Janeiro/São Paulo: Livraria Atheneu.

Brasil. (2005). Política nacional de humanização. Humaniza SUS. Disponível em: <http://portal.saude.gov.br/saude/ area.cfm?id_area=389>. (Acesso em 12/06/05).

Buss, P. M. (2000). Promoção da saúde e qualidade de vida. Ciência e Saúde Coletiva, 5(1), 163-177.

Couto, R. (2005). Entendendo a percepção hospitalar sob o olhar de profissionais e usuários do serviço. Disponível em:

<http://www.unifesp.br/dpsiq/arquivo,psicomp2.html>. (Acesso em 10/02/05).

Duarte, E. (2005). Humanização voluntária. Disponível em: <http://www.unifesp.br/dpisiq/arquivo,psicomp2.html>. (Acesso em 15/03/05).

Freyre, K. (2004). Era uma vez: laboratório de sonhos. Recife: Editora Universidade de Pernambuco - UPE.

Jeammet P. R. M, \& Consoli, S. (2000). Psicologia Médica. Rio de Janeiro: MEDSI.

Lepargneur, H. (2003). Princípios de autonomia. Em C de A. Urbin (Org.), Bioética clínica. Rio de Janeiro: Revinter.

Martins, M. C. F. (2001). Humanização das relações assistenciais de saúde: a formação do profissional de saúde. São Paulo: Casa do Psicólogo.

Mazzetti, M. (2005). Especialistas garantem benefícios de humanização de hospitais. Disponível em: <http://www1.folha.uol.com.br/folha/equilibrio/noticias/ult 263u3854.shtml>. (Acesso em 22/12/05).

Pessini, L. \& Bertachini, L. (2004). Humanização e Cuidados Paliativos. São Paulo: Loyola. 
Pessini, L. (2002). Humanização da dor e sofrimento humano no contexto hospitalar. Bioética, Brasília, Conselho Federal de Medicina, 10(2). Disponível em: <http://www. cfm.org.br>. (Acesso em 25/04/2005).

Sebastiani, R. W. \& Chiattone, H. B. C. (1991). Curso de introdução em psicologia hospital. São Paulo: Nêmeton.

Endereço para correspondência: Cileide Guedes de Melo Martins. Faculdade de Ciências Sociais Aplicada-Facisa, Rua: Rio Grande do Sul, 1442, bairro dos Estados, CEP 58030-021, João Pessoa-PB.

E-mail: remaneira@ig.com.br 